\title{
Prevalence and Risk Factors for Carriage of Methicillin-Resistant Staphylococcus aureus (MRSA) among Healthcare workers in a tertiary Institution in Nigeria.
}

\author{
Egwuatu, C.C. ${ }^{1}$, Ogunsola, F.T. ${ }^{2}$, Egwuatu T.O. ${ }^{2}$, Oduyebo O.O. ${ }^{2}$ \\ ${ }^{1}$ Department of Medical Microbiology, NnmadiAzikiwe, Nnewi, Anambra State, Nigeria. \\ ${ }^{2}$ Department of Medical Microbiology and Parasitology College of Medicine, University of Lagos, Lagos, \\ Nigeria.
}

\begin{abstract}
Detection of carriers among healthcare workers is an important component of strategies for controlling the spread of Methicillin resistant Staphylococcus aureus (MRSA) in a hospital setting. We conducted a cross sectional study on clinical and non-clinical healthcare workers at Lagos University Hospital, Nigeria. A total of 250 healthcare workers from medical and surgical units, hospital attendants (ward maids), laboratory and laundry departments were randomly sampled and screened for MRSA using nasal swabs. The overall carriage rate of MRSA was $13.6 \%$ and the prevalence was seen higher among the clinical healthcare workers than the non-clinical staff (10\% vs. 3.6\%; P<0.0001). Poor adherence to infection control practices, antibiotic use within the past three months, contact with patients with cutaneous lesions were among factors associated with MRSA in this study. Other risk factors observed included the Length of service of workers as well as use of protective clothing. However, the prevalence of MRSA carriage among healthcare workers is still low in this endemic setting compared to others in same Sub-Saharan African region or developed countries hence screening is however highly useful to identify the imported cases and also to allow prompt isolation precautions.
\end{abstract}

Keywords: carrier, infection control, prevalence, risk factors, Staphylococcus aureus

\section{Introduction}

Methicillin-resistantStapkylococcusaureus(MRSA) is a strain of Staphylococcusaureus that develops resistance through the possession of mec-A gene and which has become a major problem around the world causing hospital acquired infections and, more recently, infections in the community ${ }^{1}$.Nosocomial acquisition of MRSA has been an increasing problem worldwide and at present, this strain frequently causes hospital infections and leads to a considerable increase in morbidity and mortality ${ }^{2}$. According to the data from the National Nosocomial Infection Surveillance System (NNIS) of the Centers for Disease Control and Prevention, the rate of infections with MRSA in the intensive care units (ICU) in the US has approached $50 \%{ }^{3}$.

However, nasal Staphylococcus aureuscarriage has been on increase, affecting about $20 \%$ of the population and has been identified as a major risk factor for the pathogenesis of hospital acquired staphylococcal infections ${ }^{4}$. In Africa, the carriage rate is however low especially amongst the West African countries. A study by Kesahet al. (2003) on prevalence of Methicillin-resistant Staphylococcus aureus amongst the clinical health care workers in eight African countriesreported carrier ratesof 12.5\% in Senegal and 16.8\% in Cote D'Ivoires.

Several studies have also reported MRSA carriage by hospital staff. Muderet al. ${ }^{6}$ described five hospital employees infected with MRSA which they noted to include folliculitis, cellulites, impetigo, paronychia, and conjunctivitis while another study showed persistent MRSA carriage for 27 months in a healthcare worker $(\mathrm{HCW})^{7}$.

Various risk factors have been associated with increase nasal colonization rate of Staphylococcus aureus among health-care workers ${ }^{8}$. These factors include, staying in long-term care units, recent hospitalization, long-term antibiotic treatment, surgical intervention, presence of skin or soft tissue infections, and chronic underlying disease 9 . MRSA carriage by hospital staff normally responds to treatment with mupirocin nasal ointment, antiseptic solution for washing and shampooing and hexachlorophene powder for perineal carriers ${ }^{10}$. Despite advances in antibacterial therapy, this organism continues to pose a serious health problem and this is as a result of its development of resistance to multiple antibiotics. This in part has been attributed to high rate of antibiotic abuse and misuse especially in the developing countries like Nigeria ${ }^{11,12}$.

This multiple resistance to antibiotics has thus brought about limited therapeutic choices available for staphylococcal infections hence many hospitals try to put in place infection control measures to curb the excesses of this bacterium through frequent surveillance. This study was therefore set out todetermine the carriage rate of MRSA among health workersas well as the risk factors associated with its spread. 


\section{Material And Methods}

\section{Study design and setting}

A total of 250 health workers working in the theatre, surgical, neonatal, postnatal, labour ward as well as in the laboratory at the Lagos University Teaching Hospital were sampled. Exclusion criteria included smokers and those with respiratory infections. A questionnaire that covered demographics, previous and current antibiotic use, use of protective clothing, and general infection control procedures was administered.

All isolates of S. aureus were identified in the Department of Medical Microbiology of the College of Medicine, University of Lagos, Nigeria.

\section{Microbiological Analysis}

Samples from the anterior nares of each health worker $(\mathrm{HW})$ were swabbed with sterile moistened swabto a depth of approximately $1 \mathrm{~cm}$, and rotated five times.For each specimen, both nostrils were sampled using the same swab. Trypticase soy broth (TSB) was used as the transport medium. The samples were quickly sent to the laboratory and were inoculated onto mannitol salt agar plates and incubated at $35^{\circ} \mathrm{C}$ for $24 \mathrm{~h}$. The isolates were identified as $S$. aureus based on morphology, Gram stain, catalase test, coagulase test, and mannitol salt agar fermentation. Methicillin-susceptible S. aureus strains (MSSA) were differentiated from MRSA using Oxacillin screening test. This was done by subjecting all staphylococcus aureus isolates to plates containing $6 \mu \mathrm{g} / \mathrm{ml}$ of oxacillin in Mueller-Hinton agar supplemented with $\mathrm{NaCl}(4 \% \mathrm{w} / \mathrm{v} ; 0.68 \mathrm{~mol} / \mathrm{L})$ using Clinical and Laboratory Standards Institute (CLSI) method.

\section{Results}

A total of 250 healthcare workers were sampled to detect carriers of $S$. aureus as well as the multiantibiotic resistant strain of S. aureus, (MRSA) strains. Of these, 77 (30.8\%) were from the Laboratory, 118 from the clinical units, 55 from the theatre/ ICU/ neonatal units (Table-I). Out of these, 89 (35.6\%) were nasal carriers of S. aureus while $34(38.2 \%)$ of the 89 harboured MRSA. Overall carriage rate was $13.6 \%$.The prevalence of MRSA however, varied significantly among categories of workers ranging from $70 \%$ in the postnatal ward to $26.7 \%$ in the theatre/Intensive care unit (ICU) (Table-I). In general, there was a higher prevalence among the healthcare workers in the clinical units, theatre/ICU/neonatal, 25 (13.6\%) of 173than in the Laboratory $26(34.6 \%)$ of 77 (Table-I). It was higher among the nurses than medical doctors in the clinical setting although the difference was not significant $(\mathrm{p}<0.0001)$. It was also observed that the prevalence was higher amongst those who had worked longer in hospital especially those who had been employed for over 10 years. In this study, 56 of the 89 healthcare workers had been employed for over 10 years (Table-II).

On questioning about the knowledge of MRSA and infection control procedures, even though 23 (29.9\%) of 77 laboratory healthcare workers were aware of MRSA, 55(71.4\%) of them sometimes replaced gloves whenever they left their benches while $50(64.9 \%)$ did not use any disinfectants to wash their hands. Despite the fact that most doctors and nurses $(96.2 \%)$ were aware of nosocomial infections, only (54.3\%) always used gloves, while (53.1\%) always replaced gloves in-between patients and $32.9 \%$ always used face masks (Table-III). Antibiotic use in the preceding month was a risk factor for carriage of $S$. aureus. It was observed that 24 healthcare workers that had use antibiotic in the proceeding one month were carriers of $S$. aureus. Among these, 9 (37.5\%) had used ciprofloxacin, 8 (33.3\%) ampiclox, 5 (20.8\%) erythromycin, and one (4.2\%) Cefuroxime axetil and Sulfamethoxazole-Trimethoprim respectively.

Table 1:Colonization And Prevalence Rates of S.aureus Isolates Among Health workers

\begin{tabular}{|c|c|c|c|c|c|}
\hline \multirow[t]{2}{*}{ Ward } & \multicolumn{3}{|c|}{ Health-care worker } & \multirow{2}{*}{$\begin{array}{l}\text { Number of Health } \\
\text { workers sampled }\end{array}$} & \multirow[t]{2}{*}{ Positivity (\%) } \\
\hline & Doctor (\%) & Nurse (\%) & Lab. Scientist (\%) & & \\
\hline Laboratory & $24(31.1)$ & 0 & $53(68.8)$ & 77 & $26(33.8)$ \\
\hline Labour Ward & $12(17.1)$ & $58(89.9)$ & - & 70 & $16(22.9)$ \\
\hline Neonatal Ward & $8(38.1)$ & $13(61.9)$ & - & 21 & $10(47.6)$ \\
\hline Post natal Ward & $4(20.0)$ & $16(80.0)$ & - & 20 & $10(50.0)$ \\
\hline Surgical Ward & $2(7.2)$ & $26(92.9)$ & - & 28 & $12(42.9)$ \\
\hline Theartre/ICU & $11(32.4)$ & $23(67.7)$ & - & 34 & $15(44.1)$ \\
\hline Total & 61 & 136 & 53 & 250 & 89 \\
\hline
\end{tabular}


Table II: Association between colonization of MRSA and Length of Stay in Service.

\begin{tabular}{|l|l|l|l|}
\hline Laboratory & Colonized & Not colonized & Total \\
\hline Length of stay (years) & 0 & 0 & 0 \\
\hline$<1$ & 0 & 3 & 3 \\
\hline $1-5$ & 2 & 8 & 10 \\
\hline $5-10$ & 2 & 11 & 13 \\
\hline$>10$ & 4 & 22 & 26 \\
\hline Total & & & \\
\hline Clinical wards & 0 & 1 & 1 \\
\hline$<1$ & 0 & 2 & 2 \\
\hline $1-5$ & 4 & 8 & 12 \\
\hline $5-10$ & 6 & 17 & 23 \\
\hline$>10$ & 7 & 31 & 38 \\
\hline Total & & & 1 \\
\hline Theatre/ICU and Neonatal & 0 & 1 & 1 \\
\hline$<1$ & 0 & 1 & 3 \\
\hline $1-5$ & 1 & 2 & 20 \\
\hline $5-10$ & 7 & 13 & 25 \\
\hline$>10$ & 8 & 17 & \\
\hline Total & & & \\
\hline & & & \\
\hline & & & \\
\hline
\end{tabular}

Chi-square $=49.239, \mathrm{DF}=3, \mathrm{P}<0.0001$

Table III: Association between colonization of MRSA and adherence to UP among Healthcare workers

\begin{tabular}{|c|c|c|c|c|c|}
\hline Laboratory & & & & & \\
\hline Use of gloves & Always & Usually & Sometimes & Never & Total \\
\hline Colonized & 1 & 3 & 10 & 12 & 26 \\
\hline Not colonized & 25 & 19 & 5 & 3 & 51 \\
\hline Total & 26 & 21 & 15 & 15 & 77 \\
\hline Use of face mask & Always & Usually & Sometimes & Never & Total \\
\hline Colonized & 2 & 6 & 8 & 10 & 26 \\
\hline Not colonized & 20 & 13 & 10 & 8 & 51 \\
\hline Total & 22 & 19 & 18 & 18 & 77 \\
\hline Replacement of gloves after leaving the bench & Always & Usually & Sometimes & Never & Total \\
\hline Colonized & 2 & 6 & 8 & 10 & 26 \\
\hline Not colonized & 20 & 13 & 10 & 8 & 51 \\
\hline Total & 22 & 19 & 18 & 18 & 77 \\
\hline \multicolumn{6}{|l|}{ Clinical areas } \\
\hline Use of gloves & Always & Usually & Sometimes & Never & Total \\
\hline Colonized & 2 & 6 & 12 & 16 & 36 \\
\hline Not colonized & 35 & 27 & 11 & 5 & 78 \\
\hline Total & 37 & 33 & 23 & 21 & 114 \\
\hline Use of face mask & Always & Usually & Sometimes & Never & Total \\
\hline Colonized & 1 & 4 & 12 & 19 & 36 \\
\hline Not colonized & 38 & 24 & 9 & 7 & 78 \\
\hline Total & 39 & 28 & 31 & 26 & 114 \\
\hline Replacement of gloves in-between patients & Always & Usually & Sometimes & Never & Total \\
\hline Colonized & 4 & 8 & 17 & 7 & 36 \\
\hline Not colonized & 20 & 23 & 19 & 16 & 78 \\
\hline Total & 24 & 31 & 36 & 23 & 114 \\
\hline \multicolumn{6}{|l|}{ Theatre/ICU and Neonatal } \\
\hline Use of gloves & Always & Usually & Sometimes & Never & Total \\
\hline Colonized & 3 & 4 & 7 & 11 & 25 \\
\hline Not colonized & 8 & 6 & 4 & 2 & 25 \\
\hline Total & 11 & 10 & 11 & 13 & 45 \\
\hline Use of face mask & Always & Usually & Sometimes & Never & Total \\
\hline Colonized & 0 & 2 & 10 & 13 & 25 \\
\hline Not colonized & 7 & 5 & 4 & 4 & 20 \\
\hline Total & 7 & 5 & 4 & 4 & 20 \\
\hline Replacement of gloves in-between patients & Always & Usually & Sometimes & Never & Total \\
\hline Colonized & 2 & 5 & 10 & 8 & 25 \\
\hline Not colonized & 15 & 5 & 3 & 2 & 20 \\
\hline Total & 17 & 10 & 13 & 10 & 45 \\
\hline
\end{tabular}

Chi-square $=29.647, \mathrm{DF}=3, \mathrm{P}<0.0003$ (UP - Universal precautions) 


\section{Discussion}

This study looked at the nasal carriage rate of $S$. aureus among healthcare workers to determine their carrier rates. The carrier rate of $S$. aureus was $35.6 \%$ while that of MRSA was $13.6 \%$. The figure for the MRSA is lower than what has been reported in other West African countries like Senegal which was $12.5 \%$ and Cote D'Ivoire $16.8 \% \%^{5}$. This may be because of the laboratory workers that were studied in addition. Carrier rates amongst clinical staff were $14.5 \%$ which is much higher than the results from Senegal and Cote D'Ivoire ${ }^{5}$.

It has been shown that a high carriage rate usually precedes epidemics of MRSA and other pathogens ${ }^{13}$ and even though the colonization rate among patient was not studied, the high carriage rate among healthcare worker is an indication of poor infection control practices in the hospital. This was borne out by the fact that despite good knowledge of infection control, $4.6 \%$ of doctors and nurses did not wear gloves while $6.9 \%$ did not replace their gloves in-between patients. In studies done in USA between 1975 to 2002, prevalence of MRSA rose from $2.4 \%$ to over $50 \%$ in $2002^{14}$ and this was attributed mainly to poor infection control practices as well as ineffective chemotherapeutic control of MRSA ${ }^{15}$.

Several studies have recently proven that the longer the length of service being offered by a healthcare worker, the more the risk of becoming a colonizer of this organisms ${ }^{16,17}$. Several risk factors for MRSA were identified in this study. Length of stay was significantly associated with MRSA carriage. It was observed that workers with greater than 10 years of service were more likely to harbour MRSA. This was seen with $62.9 \%$ of healthcare workers with greater than 10 years of service having MRSA compared with $37.1 \%$ of less than 10 years.

MRSA has caused many hospital epidemics especially amongst patients in the ICU ${ }^{18}$ and has been responsible for many deaths. Some strains are resistant to all classes of antibiotics except vancomycin ${ }^{19}$. The vancomycin resistant Staphylococcus arueus (VRSA) is now identified in many ICU in particular ${ }^{20}$. Amongst the ICU/theatre/neonatal wards, the MRSA carriage was $12.7 \%$. This figure was very high as the patients here (surgical and neonates) were patients most vulnerable.

In the last few years, various chemotherapeutic agents have been identified and used to eradicate nasal carriage of MRSA and these include rifampin, clindamycin, fucidic acid, vancomycin, muprocin and recently lysostaphin. The most commonly used is muprocin, anisoleucyl-t-RNA synthase inhibitor. It inhibits bacterial isoleucyl-tRNA synthesis and thus interferes with protein synthesis. Lysostaphin, a glycylglycinendopeptidasewas developed as another alternative ${ }^{21}$. However, it has now been shown that this drug has developed resistance against this strain ${ }^{22}$. Moreover, Muprocin is expensive and widely not available in Nigeria. In addition, resistant strains have been identified ${ }^{23 ; 24}$ hence a lot of works need to be done to find other effective chemotherapeutic agents as well as enforcing infection control practices among the healthcare workers in order to reduce the rate of MRSA acquisition.

DECLARATION.

The authors hereby declare no conflict of interest.

\section{References}

[1]. Baldan, R., C. T. Din, G. Semeraro, C. Costa, P. Cichero, P. Scarpellini, M. Moro, and D. M. Cirillo. Severe community-onset infections in healthy individuals caused by community-acquired MRSA in an Italian teaching hospital.J. Hosp. Infect.2009; 72:271273 .

[2]. Cosgrove, S.E., Sakoulas, G. and Perencevich, E.N. Comparison of mortality associated with penicillin-resistant and methicillin- susceptible Staphylococcus bacteremia: A meta-analysis.Clinical Infectious Disease.(2003); 36:53-59.

[3]. National Nosocomial Infections Surveillance (NNIS) System Report, data summary from January 1992 through June 2004, issued October 2004. Am. J. Infect. Control.2004; 32:470-485.

[4]. Kluymans, J., van Belkun, A. and Verburgh, H. Nasal carriage of Staphylococcus aureus. Epidemiology, underlying mechanisms and associated risks.ClinMicrobiol Rev. 1997; 10:505-520.

[5]. Kesah, C., Redjeb, S.B., Odugbemi, T.O., Boye, C. S. B., Dosso, M. and Ndinya-Achela, J.O. Koulla-Shiro, S. Benbachir, M. and Borg, M. Prevalence of Methicillin-resistant Staphylococcus aureusin eight African hospitals and Malta.J. Clin. Microbiol.infection. 2003; 9:153-156.

[6]. Muder, R.R., Brennen, C. and Goetz, A.M. Infection with Methicillin-resistant Staphylococcus aureus among hospital employees. Infect. Control Hosp. Epidemiol. 1993; 14:576-578.

[7]. Lessing, M.P., Jordens, J.Z. and Bowler, I.C. When should the healthcare workers be screened for Methicillin-resistant Staphylococcus aureus? 1996; 34:205-210.

[8]. Nur, Y.A., Vandenbergh, M.F.O., Yusuf, M.A., Van Belkum, A. and Verbrugh, H.A. Nasal carriage of Methicillin-resistant Staphylococcus aureus among healthcare workers and peadiatric patients in two hospitals, 1975-91. Infect. Control Epidermiol.1992;13: 582-6.

[9]. Jernigan, J.A., Pullen, A.M., Flowers, L., Bell, M., and Jarvis, W.R. Prevalence of and risk factors for colonization with Methicillinresistant Staphylococcus aureusat the time of hospital admission. Infect. Control Hosp. Epidermiol.2003;24:409-414.

[10]. Sandri, A.M., Dalarosa, M.G., Ruschel, de Alcantara L., da Siva Elias, L. and Zavascki, A.P. Reduction in incidence of nosocomial methicillin-resistant Staphylococcus aureus (MRSA) infection in an intensive care unit: role of treatment with mupirocinointment and chlorhexidine baths for nasal carriers of MRSA. Infect. Control Hosp. Epidemol. 2006; 27(2):185 - 187.

[11]. Ogunsola, F.T., Kesah C.N. and OdugbemiTolu. Antimicrobial Resistance in Nigeria: An overview Nig.Qt. J. Hosp. Med. 1997;7(1):57-61 
[12]. Rotimi, V.O., Orebanjo, O.A., Banjo, T.O., Onyenefa, P.I. and Nwobu, R.N. Occurrence and susceptibility profiles of Methicillin-resistant Staphylococcus aureusin Lagos University Teaching Hospital. Cent.Afric. J. Med.1987;33:9597.

[13]. Mainous A.G., Hueston, W.J., Everett, C.J. and Diaz, V.A. Nasal carriage of Staphylococcus resistant $S$. aureus in the United States, 2001-2002.Annals of family medicine.2006; 4:132-

aureus and methicillin-

[14]. Baraff, L.J. and Talan, D.A. Compliance with Universal Precautions in a university hospital emergency department. Ann. Emerg. Med. 1989; 18:654-657.

[15]. Maki, D. Risk factors for nosocomial infection in intensive care unit -'devices vs nature' and goals for the next decade. Arch. Intern. Med.1989;149:30-35.

[16]. Eveillanid, D. A., Kim, L.E., Parks, R.L., L’Ecuyer, P.B., Mulha, S., Jeffe, D.B., Evanoff, B.A. and Fraser, V.J. Use of personal protective equipment and operating room behaviours in four surgical subspecialties: personal protective equipment and behaviours in surgery.Infect. Control Hosp. Epidemol. 1999;20(2):110-114.

[17]. Pujol, M., Pena, C., Pallares, R., Awza, J., Ayats, J., Dominguez, M.A. and Gudiol. F. NosocomialStaphylococcus aureusbacteriemia among nasal carriers of methicillin-resistant and methicillin-susceptuble strains. Am. J. med.1996; 100 (5): 509516.

[18]. Haddadin, A.S. Fappinao, S.A. and Lipsett, PA. Methicillin resistant Staphylococcus aureus (MRSA) in the intensive care unit.Postgraduate medical Journal.2002; 78:385-392.

[19]. Pouch Downes. S., Shah, J.T., Rudrik, G.R., Pupp, W.J. Brown, D. and Fridkin, S.K. Infection with vancomycin-resistant Staphylococcus aureus containing the van A resistance gene. N. $\quad$ Engl. J. Med. 2003; 348:1342-1347.

[20]. Kokai-Kun, J.F., Walsh, S.M., Chanturiya, T. and Mond, J.J. Lysostaphin cream eradicatesStaphylococcus aureus nasal colonization in cotton rat model. AntimicrobAgents Chemother.2003;47:1589-1597.

[21]. Kusuma, C.M. and Kokai-kun, J.F. Comparison of four methods for determing lysostaphinsusceptibility of various strains of Staphylococcus aureus. Antimicrob.Agents Chemother.2005; 49: 3256-3263.

[22]. Cookson, B.D. Mupirocin resistance in Staphylococci.J. Antimicrob. Chemother. 1990;25:497-503.

[23]. Dawson, S.L Fuin, J., McCulloch, S., Kilvington, and Lewis, D. Mupirocin-resistant MRSA. J. Hosp. Infect. 1994; 28:75-78.

[24]. Leski, T,A.M., Gniadkowski, A., Skoczynska, E., Stefaniuk, K, Trzcinski and Hryiewics, W. of mupirocinresistant staphylococci in a hospital in Warsaw, Poland, due to plasmid transmission and clonal spread of several strains. $J$. Clin. Microbiol.1999; 37:2781-2788. 